\title{
Talking about the Artistic Elements in Costume Design
}

\author{
Ping Wang \\ Guangdong University of Science \& Technology, Dongguan 523083, China
}

Keywords: art, element, costume design.

\begin{abstract}
Costume design is not only an art, but also a means to explore the relationship between material and form. We not only to analyze the art elements of fashion design, but also from a number of angles to analyze these artistic elements. Because when we understand the artistic elements of the way and the relevant rules thoroughly can we master the inherent meaning of fashion design art.Then we can design art development more colorful and meet the needs of modern clothing trends.
\end{abstract}

\section{Introduction}

The art elements in the design of clothing are more extensive. In theory, it contains geometric, psychological and physical and other fields. So if the costume designer wants to design the clothing to meet people's needs, they must have an advanced design concept of a train of thought. As they develop along the development of the times, they can be very confident in the artistic elements of fashion design. In the continuous progress of society, people's aesthetic is also undergoing constant changes, and the artistic can have some fashion design to meet the people's visual laws and aesthetic principles of the deepening requirements of continuous improvement. We through the clothing design and artistic elements of the deep in-depth analysis so as to explore the clothing contained in the design of the artistic connotation. We can show the colorful side of the clothing so as to meet the modern people on the gorgeous fashion needs.

\section{The meaning of a clothing design}

The so-called clothing design is actually a dress after the human body of a state design. From a broad sense, it can be understood as in a creative imagination, the minds of the idea to create a specific activity. In the costume design, it should be noted that it designed the clothing must meet people's psychological needs and physiological needs. The only way to make clothing design is to meet the needs of people perfect.

\section{From all angles analysis of fashion design art elements}

The so-called element is the material and form as a material, in accordance with the visual effects and physical and psychological, such as the combination. It focuses on the physical laws of modeling and perception of the psychological laws, so the design and production of clothing modeling process are the three-dimensional form of the modeling process. In the analysis of artistic elements, we must be clear that the concept of line. Face is the most basic concept of art. Because any object can be reduced to point, line, surface, and point, line, surface, so it can constitute any shape. In the costume design process, the point of the smart embellishment and the line of free interspersed are the subjects of the variable combination. This point, line, surface of the integrated use of clothing can make the performance of space and become more colorful. From the art of clothing design elements to analyze the shape of clothing, we can find it is actually a combination of plane relationship. And thus in the clothing structure of the structural line, some key places are the transition between the various forms of the formation of these twists. Turns in the clothing can also be expressed as provincial and so on. In addition, the combination of various surfaces will also show a lot of bumps on the human body changes, such as the pits are the waist position, and the bump is the chest and hip point. So from the perspective of clothing modeling, art elements can be a scientific expression of the connotation of 
clothing. With the rapid development of modern society, people's aesthetic is constantly changing. The requirements of the clothing is also getting higher and higher, which requires the costume designer in the design of clothing. The three-dimensional composition of the clothing in the rugged place is special design and processing. In addition, they also have the creative use of a variety of decorations to match the clothing, which in the clothing is to show the artistic elements, and then reflect the unique beauty of clothing to meet the people in the trend of the demand for clothing.

\section{Clothing in the specific role of artistic elements}

\subsection{Art elements can enhance the expression of clothing}

In the modern design, the use of more methods is mainly to block, surface material and wire composed of three-dimensional form. This approach can greatly enhance the performance of clothing. Clothing is generally composed of numerous different structures, uneven thickness and density of different strip of wire composition. It is the overall sense of the people from the clear and complex combination of the composition of the state, so that the beauty and rhythm will be more flexible. And the combination of wire and noodles constitute the clothing from the overall effect will be more complex. It is the dynamic and virtual wire and the material in the static and real contrast. In the design of clothing can be used in a variety of methods at the same time, so that it not only can open the idea of design so as to stimulate the designer's inspiration, but also through these constitute the way to express the fabric expression of full play. The creative space of clothing is the maximum of the excavation out.

\subsection{Art elements can enrich the appeal of clothing art}

If we put the art of fashion design as a three-dimensional art, you will find that clothing design is actually embodies the overall charm of space as a composition of art, it is the main study of the human body and its configuration occupied space, so clothing design must In accordance with the law of the law of development. In the fashion design, it is often emphasized to the composition of the main sense of space, layering and illusion, etc. They can greatly enhance the artistic appeal of clothing. First of all, fashion designers in the design of clothing can take into account the body's movement and clothing comfort. It must have a certain sense of the amount of law. Secondly, the designer in the costume design can take into account the three-dimensional decoration and space cascade relations, so this requires a sense of space to have a sense of space. The so-called illusion is actually a kind of psychological reaction, but it is also a means of expression of art. The design of clothing should be appropriate to use everyone's visual illusion, which can not only deal with the size of clothing modeling, light and shade. And other relations can play the finishing touch of visual effects. Although there is the composition of the different types of art, expression is different and their artistic nature is the same.

\subsection{Art elements can enhance the fashion sense of clothing}

There are many kinds of art classification, art and fashion have always been interrelated with each other. Fashion art extensively contains architectural, music, painting, literature, sculpture, architectural dance, drama, film and other aesthetic forms. Such as the medieval Gothic style so that fashion art shine; fashion rhythm and the rhythm of music. The painting in the introduction of Dadaism, subjectivism, surrealist design style, popular pop in recent years Art and postmodernism in the use of clothing and so on are all these. It is the designer of the integration of other arts through ao as to improve their own unique design style.

Fashion to fashion as a criterion is the United States and the new core content. Yves Saint Laurent from the painting to absorb inspiration can create a series of Monterey and a series of highly artistic characteristics of high-end fashion, which shows amazing charm and designer himself elegant art. Designer Versace design will be the pop artist Warhol creation of the oil painting "Marilyn Monroe" the head cleverly through the combination. The move is bold and no lack of clothing Smart beauty. Pierre Cardin from the Forbidden City of China can get inspiration, creating a wind and the world fashion style. Designers should be practical and aesthetic from the two aspects of the design to make 
the clothing in the original functional properties on the basis of adding more fun, so that clothing as a whole can reflect more innovation and Visual breakthrough effect.

\subsection{Art elements can achieve many other unique values}

Specifically, art has a unique value that science and other disciplines can not achieve. First of all, what is the indispensable way of technology and science? The first example is a car. The car makes the following impossible things: the city spans and the public will shrink. The malls are sprinkled. Thus, the suburbs become a necessity, which itself is a necessity. I would like to use another example is the phone. The phone has become the nerve endings of our society. The phone saved life through rapid illness, accidents or other emergencies. More importantly, it makes multi-storey buildings and office possible so that we can be connected anywhere. At all times, it can make the world a small village possible. Finally, it makes it impossible to shelve that is indispensable. Art is not the case, art is different from the technology itself. Art has real value, eternal value and independent value. In general, the effect of art on mankind is like rainy sour seeds. Seeds can make it mouth, boom, and finally bloom. Art nourishes our souls can make it self-consciousness, sublimation, and finally creation.

The value of art can not be replaced. Its role is unique. We use our eyes, ears and other senses to feel the outside world. Their role can not be replaced, once one of them stops working, others can only compensate for it, but will never be restored. Its function is unique. Art is the same, it helps humans connect to deeper emotions, penetrate the surface, go beyond the appearance of the surface, and open the new ways of knowing the world.

Art can promote and accelerate the development of technology or science while helping art from science is very limited if there is. Such an example is so great that almost every well-known scientist is considered to be good, or like some art class. This example gives me the deepest impression is Kepler. In his "harmony of the world" works, he says that the movement of the planets is like the movement of the notes in the sky. Just like a student's music learn how the details can be put together, bitter, and then form a good, not mediocre, work. Kepler had to put a lot of information, which left him with the use, it was more difficult to calculate the law of motion that they found his planets. It's hard to imagine that there is no computer, how can we end this boring repetition, Kepler, and from my point of view, the complex work. Perhaps the explanation should be, there are some things that help him know the data should be, not just try his luck.

In many ways, the Germans have beaten people in the world of education. But their education does not act as a barbaric enough barrier. What is the problem of their education, in the words of Weissel: "It emphasizes the theory, not the values, not the concept of man, not the consciousness, not the answer to the question, not the question, the thought and the efficiency, Not the conscience. "History can" tell "the future, but they can, on the other hand, reveal all that is now. It is time to review our own. This is certainly not enough to learn from the West, more importantly, may be able to learn from our ancient thinkers. Anyway, you have to go back to what one day you threw out. It will not be too far.

Here, I use a table to summarize the main role of artistic elements in fashion design, each effect will have a corresponding major explanation. As shown in Table 1 below.

Table 1: the specific role of the artistic elements in clothing

\begin{tabular}{|c|c|c|c|c|}
\hline Specific role & Enhance expressive force & Rich in appeal & Enhance fashion sense & Other value \\
\hline \multirow{2}{*}{$\begin{array}{c}\text { To the block material, } \\
\text { performance }\end{array}$} & $\begin{array}{c}\text { Sense of } \\
\text { feeling, sense } \\
\text { surface material and wire } \\
\text { structure of the } \\
\text { three-dimensional form } \\
\text { of hierarchy } \\
\text { and illusion }\end{array}$ & $\begin{array}{c}\text { Architecture, music, } \\
\text { painting, literature, } \\
\text { sculpture, architectural } \\
\text { dance, drama, film and } \\
\text { other aesthetic forms }\end{array}$ & $\begin{array}{c}\text { Car, senses, } \\
\text { technology } \\
\text { or science }\end{array}$ \\
\hline
\end{tabular}

\section{Conclusion}

Art element is a performance method of costume design. In the costume design process, we not only to understand its intrinsic meaning, but also from all angles to its in-depth analysis. Art elements can not only enhance the expression of clothing design, but also enrich the appeal of fashion design. 
Only by following the rules of artistic elements, fashion designers can make people have a deeper understanding of fashion design. They designed the clothing to be more perfect, but also better meet the current needs of people in the trend.

\section{References}

[1] Zhou Feng; on the plane composition in the application of clothing design [J]; decoration; 2011-06

[2] Yu Fang; striped costume design and composition art [J]; Huizhou University (Social Science Edition); 2012-01

[3] Ye Hui, Yao Guizhen; Analysis of retro elements in fashion design [J]; Shandong Textile Economy; 2012-10

[4] Li Yan Zu: "the beauty of creation", China People's University Press, 2000 